\title{
Uji Efek Analgesik Ekstrak Daun Jarak Pagar (Jatropha Curcas L.) terhadap Tikus Wistar (Rattus Norvegicus)
}

\author{
${ }^{1}$ Oras N. B. Yensenem \\ ${ }^{2}$ Jane Wuisan \\ ${ }^{2}$ Henoch Awaloei
}

\author{
${ }^{1}$ Program Studi Pendidikan Dokter Fakultas Kedokteran Universitas Sam Ratulangi Manado \\ ${ }^{2}$ Bagian Farmakologi dan Terapi Fakultas Kedokteran Universitas Sam Ratulangi Manado \\ E-mail: orasyensenem@yahoo.com
}

\begin{abstract}
Indonesia is a tropical country with the second largest biodiversity in the world after Brazil. Jatropha curcas (Jatropha curcas L.) was believed as a pain reliever (analgesic). This study was aimed to prove the analgesic effect of Jatropha curcas leaf extract on Wistar rats (Rattus norvegicus). This was an experimental study using hot stimulus method in the form of temperature of $65^{\circ} \mathrm{C}$. Subjects were 15 male Wistar rats divided into 5 groups. Group 1, the negative control group; group 2, the positive control group given paracetamol 40 $\mathrm{mg} / \mathrm{kgBW}$; and 3 treatment groups (groups 3, 4, and 5) given Jatropha curcas extract in several doses $(300 \mathrm{mg} / \mathrm{kgBW}, 600 \mathrm{mg} / \mathrm{kgBW}$, and $1200 \mathrm{mg} / \mathrm{kgBW})$. Observation of Wistar rat respons (licking and jumping) was performed for 1 minute at minutes -30, 60, 90, and 120 after treatment. The results showed that the mean values of response against heat decreased in accordance to time and reached the lowest values at minute 120, except group 5 (the extract dose of $1200 \mathrm{mg} / \mathrm{kg} \mathrm{BW}$ ) which reached the lowest value at minute 90 . Overall, the lowest mean value was found in group 4 (the extract dose of $600 \mathrm{mg} / \mathrm{kg} \mathrm{BW}$ ). Conclusion: Jatropha curcas (Jatropha curcas L.) leaf extract had an analgesic effect on Wistar rats (Rattus norvegicus).
\end{abstract}

Keywords: Jatropha curcas L., Rattus norvegicus, analgesic

\begin{abstract}
Abstrak: Indonesia merupakan negara beriklim tropis dengan keaneka ragaman hayati terbesar kedua di dunia setelah Brazil. Penelitian ini bertujuan untuk mengetahui efek analgesik pemberian ekstrak daun jarak pagar (Jatropha curcas L.) pada tikus Wistar (Rattus norvegicus). Jenis penelitian ini ialah eksperimental dengan mengguna-kan metode rangsang panas berupa suhu $65^{\circ} \mathrm{C}$. Subjek penelitian mengunakan hewan uji berupa tikus Wistar (Rattus norvegicus) jantan sebanyak 15 ekor yang dibagi menjadi 5 kelompok, yaitu: Kelompok kontrol negatif; kelompok kontrol positif yang diberikan parasetamol $40 \mathrm{mg} / \mathrm{kgBB}$; dan 3 kelompok perlakuan yang diberikan ekstrak jarak pagar (Jatropha curcas L.), dengan dosis $300 \mathrm{mg} / \mathrm{kgBB}, 600 \mathrm{mg} / \mathrm{kgBB}$, dan $1200 \mathrm{mg} / \mathrm{kgBB}$. Pengamatan terhadap respon tikus Wistar berupa jilat dan lompat dilakukan selama 1 menit pada menit ke-30, 60, 90, dan 120 setelah pemberian ekstrak jarak pagar. Hasil penelitian mendapatkan bahwa terdapat penurunan nilai rerata respons terhadap panas yang sesuai dengan perlangsungan waktu kecuali pada kelompok 5 (dosis ekstrak daun jarak pagar $1200 \mathrm{mg} / \mathrm{kg} \mathrm{BB}$ ) yang mencapai nilai terendah pada menit ke-90. Secara keseluruhan, nilai rerata respons yang terendah didapatkan pada kelompok 4 (dosis ekstrak daun jarak pagar $600 \mathrm{mg} / \mathrm{kg} \mathrm{BB}$ ) pada menit ke-120. Simpulan: Ekstrak daun jarak pagar (Jatropha curcas L.) memiliki efek analgesik terhadap tikus Wistar (Rattus norvegicus)
\end{abstract}

Kata kunci: Jatropha curcas L., Rattus norvegicus, analgesic 
Menurut The International Association for the Study of Pain (IASP), nyeri didefinisikan sebagai pengalaman sensoris atau emosional yang tidak menyenangkan yang berhubungan dengan kerusakan jaringan atau berpotensi akan menyebabkan kerusakan jaringan. ${ }^{1}$ Nyeri adalah sensasi subjektif rasa tidak nyaman yang biasanya berkaitan dengan kerusakan jaringan aktual atau potensial. ${ }^{2}$ Persepsi yang disebabkan oleh rangsangan yang berpotensi menimbulkan kerusakan jaringan disebut nosiseptik.Nosiseptik merupakan langkah awal proses nyeri. Reseptor neurologik yang dapat membedakan antara rangsangan nyeri dan rangsangan lain ialah nosiseptor. Analgesik atau obat penghalang nyeri adalah zat-zat yang mengurangi atau menghalau rasa nyeri tanpa menghilangkan kesadaran. Atas dasar farmakologiknya, analgesik dibagi dalam 2 kelompok besar yaitu analgesik perifer (non-opioid), terdiri dari obat-obat yang tidak bersifat narkotik dan tidak bekerja sentral; dan analgesik narkotik (opioid) yang khusus digunakan untuk menghalau rasa nyeri hebat. ${ }^{3-5}$

Jarak pagar (Jatropha curcas L.) dipercaya sebagai tanaman berkhasiat penghilang rasa nyeri (analgesik). ${ }^{6-11}$ Penelitian ini bertujuan untuk mengetahui apakah ekstrak daun jarak pagar (Jatropha curcas L.) memiliki efek analgesik.

\section{METODE PENELITIAN}

Jenis penelitian ini ialah eksperimental. Penelitian dilakukan sejak bulan September 2015 sampai Januari 2016 di Laboratorium Farmakologi dan Terapi Fakultas Kedokteran Universitas Sam Ratulangi Manado. Penelitian ini menggunakan tikus Wistar (Rattus norvegicus) sebanyak 15 ekor sebagai hewan uji yang dibagi dalam lima kelompok masing-masing terdiri dari 3 ekor yaitu: Kelompok 1 sebagai kontrol positif, diberi obat parasetamol; kelompok 2 sebagai kontrol negatif, hanya diberi pakan dan minum; kelompok 3 sebagai kelompok perlakuan yang diberi ekstrak daun jarak pagar dengan dosis 300 $\mathrm{mg} / \mathrm{kgB}$; kelompok 4 sebagai kelompok perlakuan yang diberi ekstrak daun jarak pagar dengan dosis $600 \mathrm{mg} / \mathrm{kgB}$; dan kelompok 5 sebagai kelompok perlakuan yang diberi ekstrak daun jarak pagar dengan dosis $1200 \mathrm{mg} / \mathrm{kgBB}$

Hewan uji yang digunakan ialah tikus Wistar (Rattus norvegicus) dengan berat sekitar 200 gram kemudian dipuasakan selama $\leq 10$ jam.

Ekstrak daun jarak pagar (Jatropha curcas L.) dibuat dengan metode maserasi dan menggunakan pelarut etanol $80 \%$. Dosis ekstrak daun jarak pagar yang digunakan untuk kelompok perlakuan ialah: kelompok 3 sebesar $300 \mathrm{mg} / \mathrm{kgBB}$, kelompok 4 sebesar $600 \mathrm{mg} / \mathrm{kgBB}$, dan kelompok 5 sebesar $1200 \mathrm{mg} / \mathrm{kgBB}$. Untuk tikus yang beratnya $200 \mathrm{~g}$ diberikan $60 \mathrm{mg}$, $120 \mathrm{mg}$, dan $240 \mathrm{mg}$. Ekstrak pekat ditimbang $2 \mathrm{~g}$ dan dilarutkan dalam akuades $10 \mathrm{ml}$, diambil $0,3 \mathrm{ml}$ dan diberikan pada kelompok perlakuan pertama, 0,6 ml untuk perlakuan kedua, dan 1,2 ml untuk perlakuan ketiga.

Pada kontrol positif, dosis yang diberikan pada tikus Wistar dengan berat $200 \mathrm{~g}$ ialah 200/1000 g x $40 \mathrm{mg}=8 \mathrm{mg} / 200 \mathrm{~g}$ berat badan tikus Wistar. Tablet parasetamol $500 \mathrm{mg}$ dicampur dengan akuades $5 \mathrm{ml}$, diambil 0,08 $\mathrm{ml}$ dan diberikan pada tikus Wistar.

Pemberian zat uji dilakukan per oral menggunakan semprit $1 \mathrm{ml}$ dan sonde lambung. Pengujian efek analgesik menggunakan metode rangsang panas dengan suhu $65^{\circ} \mathrm{C}$ sebagai stimulus nyeri. Data dinilai dari respon tikus wistar yang melompat atau menjilat kaki.

Hasil pengamatan terhadap respon hewan uji masing-masing kelompok perlakuan dicatat dan kemudian dibandingkan.

\section{HASIL PENELITIAN}

Data hasil penelitian diperoleh dari 5 kelompok hewan uji yakni kelompok kontrol positif, kelompok kontrol negatif, kelompok perlakuan pertama (kelompok 3), kelompok perlakuan kedua (kelompok 4), dan kelompok perlakuan ketiga (kelompok 5). Setiap kelompok hewan uji terdiri dari 3 ekor tikus Wistar.

Tabel 1 memperlihatkan terdapatnya 
kecenderungan penurunan nilai jumlah dan rerata respons tikus Wistar terhadap stimuli panas (L. Lompat; J, jilat; T, total) dengan perlangsungan waktu dan nilai terendah tercapai pada menit ke-90.

Tabel 2 memperlihatkan bahwa tidak terdapat kecenderungan penurunan nilai jumlah dan rerata respons tikus Wistar terhadap stimuli panas dengan perlangsungan waktu.

Tabel 3 memperlihatkan terdapatnya kecenderungan penurunan nilai jumlah dan rerata respons tikus Wistar terhadap stimuli panas dengan perlangsungan waktu dan nilai terendah tercapai pada menit ke-120.

Tabel 4 memperlihatkan terdapatnya kecenderungan penurunan nilai jumlah dan rerata respons tikus Wistar terhadap stimuli panas dengan perlangsungan waktu dan nilai terendah tercapai pada menit ke- 120 .

Tabel 5 memperlihatkan bahwa walaupun terdapat kecenderungan penurunan nilai jumlah dan rerata respons tikus Wistar terhadap stimuli panas dengan perlangsungan waktu namun nilai terendah tercapai pada menit ke-90.

Tabel 1. Hasil pengamatan respon kelompok kontrol positif (parasetamol)

Jumlah dan rerata respon tikus Wistar

\begin{tabular}{|c|c|c|c|c|c|c|c|c|c|c|c|c|c|c|c|}
\hline \multirow{3}{*}{ Subjek } & \multirow{2}{*}{\multicolumn{3}{|c|}{$\begin{array}{l}\text { Sebelum } \\
\text { perlakuan }\end{array}$}} & \multicolumn{12}{|c|}{ Setelah perlakuan (pemberian parasetamol) menit ke- } \\
\hline & & & & \multicolumn{3}{|c|}{30} & \multicolumn{3}{|c|}{60} & \multicolumn{3}{|c|}{$90^{\prime}$} & \multicolumn{3}{|c|}{$120^{\prime}$} \\
\hline & $\mathrm{L}$ & $\mathrm{J}$ & $\mathrm{T}$ & $\mathrm{L}$ & $\mathrm{J}$ & $\mathrm{T}$ & $\mathrm{L}$ & $\mathrm{J}$ & $\mathrm{T}$ & $\mathrm{L}$ & $\mathrm{J}$ & $\mathrm{T}$ & $\mathrm{L}$ & $\mathrm{J}$ & $\mathrm{T}$ \\
\hline I & 7 & 5 & 12 & 5 & 3 & 8 & 4 & 4 & 8 & 5 & 4 & 9 & 6 & 5 & 11 \\
\hline II & 5 & 6 & 11 & 4 & 3 & 7 & 5 & 4 & 9 & 5 & 5 & 10 & 7 & 6 & 13 \\
\hline III & 3 & 4 & 7 & 5 & 2 & 7 & 4 & 3 & 7 & 6 & 3 & 9 & 6 & 4 & 10 \\
\hline Jumlah & & & 30 & & & 22 & & & 24 & & & 28 & & & 34 \\
\hline Rerata & & & 10 & & & 7,3 & & & 8 & & & 9,3 & & & 11,3 \\
\hline
\end{tabular}

Tabel 2. Hasil pengamatan respon kelompok kontrol negatif

\begin{tabular}{|c|c|c|c|c|c|c|c|c|c|c|c|c|c|c|c|}
\hline \multirow{4}{*}{ Subjek } & \multicolumn{15}{|c|}{ Jumlah dan rerata respon tikus Wistar } \\
\hline & \multirow{2}{*}{\multicolumn{3}{|c|}{$\begin{array}{l}\text { Sebelum } \\
\text { perlakuan }\end{array}$}} & \multicolumn{12}{|c|}{ Setelah perlakuan (pemberian akuades) menit ke - } \\
\hline & & & & \multicolumn{3}{|c|}{$30^{\prime}$} & \multicolumn{3}{|c|}{$60^{\prime}$} & \multicolumn{3}{|c|}{$90^{\prime}$} & \multicolumn{3}{|c|}{$120^{\prime}$} \\
\hline & $\mathrm{L}$ & $\mathrm{J}$ & $\mathrm{T}$ & $\mathrm{L}$ & $\mathrm{J}$ & $\mathrm{T}$ & $\mathrm{L}$ & $\mathrm{J}$ & $\mathrm{T}$ & $\mathrm{L}$ & $\mathrm{J}$ & $\mathrm{T}$ & $\mathrm{L}$ & $\mathrm{J}$ & $\mathrm{T}$ \\
\hline I & 9 & 3 & 12 & 6 & 4 & 10 & 7 & 5 & 12 & 5 & 4 & 9 & 6 & 5 & 11 \\
\hline II & 6 & 4 & 10 & 5 & 5 & 10 & 6 & 5 & 11 & 5 & 5 & 10 & 7 & 6 & 13 \\
\hline III & 7 & 2 & 9 & 6 & 4 & 10 & 6 & 4 & 10 & 6 & 4 & 10 & 5 & 6 & 11 \\
\hline Jumlah & & & 31 & & & 30 & & & 33 & & & 29 & & & 35 \\
\hline Rerata & & & 10,3 & & & 10 & & & 11 & & & 9,6 & & & 11,6 \\
\hline
\end{tabular}

Tabel 3. Hasil pengamatan respon kelompok perlakuan ekstrak daun jarak pagar (Jatropha curcas L.) dengan dosis $300 \mathrm{mg} / \mathrm{kgBB}$

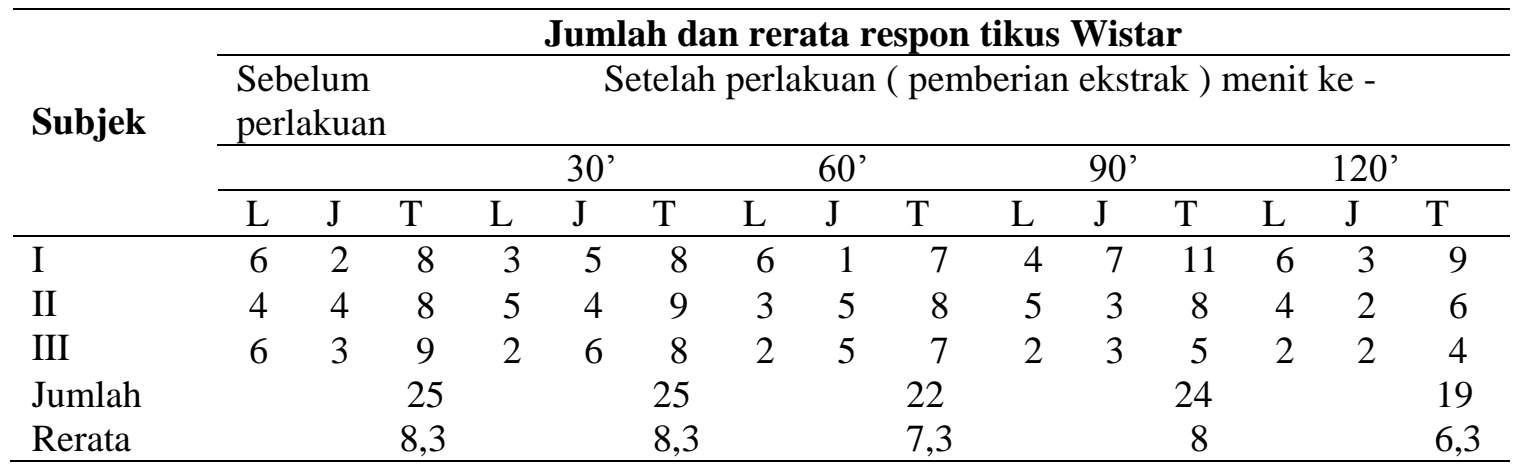


Tabel 4. Hasil pengamatan respon kelompok perlakuan ekstrak daun jarak pagar (Jatropha curcas L.) dengan dosis $600 \mathrm{mg} / \mathrm{kgBB}$

\begin{tabular}{|c|c|c|c|c|c|c|c|c|c|c|c|c|c|c|c|}
\hline \multirow{4}{*}{ Subjek } & \multicolumn{15}{|c|}{ Jumlah dan rerata respon tikus Wistar } \\
\hline & \multirow{2}{*}{\multicolumn{3}{|c|}{$\begin{array}{l}\text { Sebelum } \\
\text { perlakuan }\end{array}$}} & \multicolumn{12}{|c|}{ Setelah perlakuan (pemberian ekstrak) menit ke - } \\
\hline & & & & \multicolumn{3}{|c|}{$30^{\prime}$} & \multicolumn{3}{|c|}{$60^{\prime}$} & \multicolumn{3}{|c|}{$90^{\prime}$} & \multicolumn{3}{|c|}{$120^{\prime}$} \\
\hline & $\mathrm{L}$ & $\mathrm{J}$ & $\mathrm{T}$ & $\mathrm{L}$ & $\mathrm{J}$ & $\mathrm{T}$ & $\mathrm{L}$ & $\mathrm{J}$ & $\mathrm{T}$ & $\mathrm{L}$ & $\mathrm{J}$ & $\mathrm{T}$ & $\mathrm{L}$ & $\mathrm{J}$ & $\mathrm{T}$ \\
\hline I & 6 & 4 & 10 & 7 & 3 & 10 & 2 & 5 & 7 & 4 & 4 & 8 & 2 & 1 & 3 \\
\hline II & 6 & 6 & 12 & 2 & 5 & 7 & 1 & 5 & 6 & - & 4 & 4 & - & - & - \\
\hline III & 7 & 4 & 11 & 5 & 5 & 10 & 3 & 3 & 6 & 6 & 2 & 8 & 3 & 3 & 6 \\
\hline Jumlah & & & 33 & & & 27 & & & 19 & & & 20 & & & 9 \\
\hline Rerata & & & 11 & & & 9 & & & 6,3 & & & 6,6 & & & 3 \\
\hline
\end{tabular}

Tabel 5. Hasil pengamatan respon kelompok perlakuan ekstrak daun jarak pagar (Jatropha curcas L.) dengan dosis $1200 \mathrm{mg} / \mathrm{kgBB}$

\begin{tabular}{|c|c|c|c|c|c|c|c|c|c|c|c|c|c|c|c|}
\hline \multirow{4}{*}{ Subjek } & \multicolumn{15}{|c|}{ Jumlah dan rerata respon tikus Wistar } \\
\hline & \multicolumn{3}{|c|}{$\begin{array}{l}\text { Sebelum } \\
\text { perlakuan }\end{array}$} & \multicolumn{12}{|c|}{ Setelah perlakuan (pemberian ekstrak) menit ke - } \\
\hline & & & & \multicolumn{3}{|c|}{30 ' } & \multicolumn{3}{|c|}{$60^{\prime}$} & \multicolumn{3}{|c|}{90 ' } & \multicolumn{3}{|c|}{$120^{\prime}$} \\
\hline & $\mathrm{L}$ & $\mathrm{J}$ & $\mathrm{T}$ & $\mathrm{L}$ & $\mathrm{J}$ & $\mathrm{T}$ & $\mathrm{L}$ & $\mathrm{J}$ & $\mathrm{T}$ & $\mathrm{L}$ & $\mathrm{J}$ & $\mathrm{T}$ & $\mathrm{L}$ & $\mathrm{J}$ & $\mathrm{T}$ \\
\hline I & 7 & 5 & 12 & 7 & - & 7 & 4 & - & 4 & 3 & - & 3 & 2 & 6 & 8 \\
\hline II & 6 & 4 & 10 & 5 & 1 & 6 & 6 & 2 & 8 & 1 & 1 & 2 & 3 & 2 & 5 \\
\hline III & 9 & 7 & 16 & 6 & 3 & 9 & 2 & 5 & 7 & 1 & 5 & 6 & 2 & 5 & 7 \\
\hline Jumlah & & & 38 & & & 22 & & & 19 & & & 11 & & & 20 \\
\hline Rerata & & & 12,6 & & & 7,3 & & & 6,3 & & & 3,6 & & & 6,6 \\
\hline
\end{tabular}

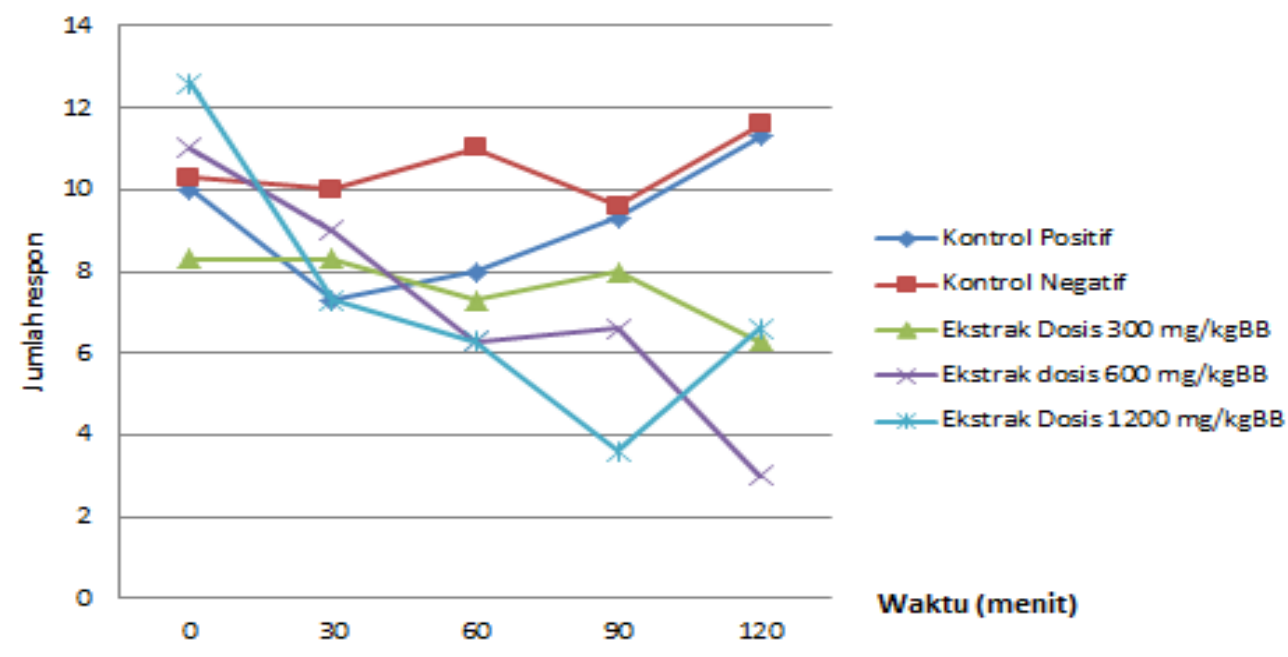

Gambar 1. Grafik perbandingan rata-rata jumlah respon

\section{BAHASAN}

Penelitian ini dilakukan untuk mengetahui ada tidaknya efek analgesik dari ekstrak daun jarak pagar dengan menggunakan metode rangsang panas (hot plate method) yang diuji pada tikus Wistar.
Rangsangan yang diberikan pada hewan uji yaitu berupa rangsangan panas dengan suhu $65^{\circ} \mathrm{C}$. Respon tikus yang dinilai berupa gerakan menjilat kaki atau melompat. Efek analgesik dapat ditunjukkan dengan berkurangnya jumlah respon tikus Wistar. 
Rerata respon tikus pada kelompok kontrol positif sebelum perlakuan 10 kali; setelah perlakuan menit ke-30 menurun menjadi 7,3 (dibulatkan menjadi 7); menit ke-60 meningkat menjadi 8 kali; menit ke90 meningkat menjadi 9,3 kali (dibulatkan menjadi 9); dan pada menit ke-120 meningkat menjadi 11,3 kali (dibulatkan menjadi 11) (Tabel 1). Parasetamol mencapai kadar puncak dalam plasma dalam waktu 30-60 menit dan memiliki paruh waktu 1-3 jam. ${ }^{4}$

Pada kontrol negatif, jumlah dan rerata respons tikus Wistar terhadap stimuli panas pada setiap menit observasi lebih tinggi daripada kelompok 1 (Tabel 2).

Efek analgesik ekstrak daun jarak pagar mulai terlihat di menit ke-120 pada dosis $300 \mathrm{mg} / \mathrm{kgBB}$. Hal ini terlihat pada rerata respon tikus Wistar yaitu sebelum perlakuan, rerata respon 8,3 kali (dibulatkan menjadi 8); pada menit ke-30 rerata respon masih 8 kali; menit ke-60 menurun menjadi 7,3 kali (dibulatkan menjadi 7); menit ke-90 rerata respon meningkat menjadi 8 kali; dan menit ke-120 menurun menjadi 6,3 kali (dibulatkan menjadi 6) (Tabel 3). Penurunan ini diduga karena efek flavanoid. ${ }^{12}$

Pada dosis $600 \mathrm{mg} / \mathrm{kgBB}$, efek analgesik mulai terlihat pada menit ke-30 setelah perlakuan dengan rerata respon tikus sebelum perlakuan 11 kali dan pada menit ke-30 setelah perlakuan menurun menjadi 9 kali; menit ke-60 menurun menjadi 6,3 kali (dibulatkan menjadi 6); menit ke-90 meningkat menjadi 6,6 kali (dibulatkan menjadi 7); dan pada menit ke120 menurun menjadi 3 kali (Tabel 4).

Pada dosis $1200 \mathrm{mg} / \mathrm{kgBB}$, efek analgesik mulai terlihat pada menit ke-30, rerata respon tikus sebelum perlakuan 12,6 kali (dibulatkan menjadi 13); pada menit ke-30 menurun menjadi 7,3 kali (di bulatkan menjadi 7); menit ke-60 menurun menjadi 6,3 kali (dibulatkan menjadi 6); menit ke 90 menurun menjadi 3,6 (dibulatkan menjadi 4); lalu menit ke-120 meningkat menjadi 6,6 kali (dibulatkan menjadi 7) (Tabel 5).

Secara keseluruhan pada kelompok perlakuan (kelompok 3, 4, dan 5) terlihat penurunan nilai rerata respons terhadap panas dengan perlangsungan waktu kecuali pada kelompok 5 (dosis ekstrak daun jarak pagar $1200 \mathrm{mg} / \mathrm{kg} \mathrm{BB}$ ) yang mencapai nilai terendah pada menit ke-90. Nilai rerata respons yang terendah didapatkan pada kelompok 4 (dosis ekstrak daun jarak pagar $600 \mathrm{mg} / \mathrm{kg} \mathrm{BB}$ ) (Tabel 4, Gambar 1).

\section{SIMPULAN}

Dari hasil penelitian dapat disimpulkan bahwa ekstrak daun jarak pagar memiliki efek analgesik terhadap tikus Wistar.

\section{DAFTAR PUSTAKA}

1. Setiyohadi B, Sumariyono, Kasjmir YI, Isbagio H, Kalim H. Nyeri. In: Buku Ajar Ilmu Penyakit Dalam Jilid III (5th ed). Jakarta: InternaPublishing,; 2009; p. 2483-4.

2. Corwin EJ. Buku Saku Patofisiologi. Jakarta: EGC, 2000; p. 222.

3. Tjay TH, Raharja K. Obat-Obat Penting; Khasiat, Penggunaan dan Efek Sampingnya (6th ed). Jakarta: PT Elex Media Komputindo, 2007; p. 312.

4. Wilmana PF, Gan S. Analgesik-antipiretik, analgesik anti-inflamasi non steroid, dan obat gangguan sendi lainnya. In: Farmakologi dan Terapi (5th ed). Jakarta: Departemen Farmakologi dan Teraupetik Fakultas Kedokteran Universitas Indonesia, 2008; p. 230-2, 237-38.

5. Neal MJ. At a Glans Farmakologi Medis (5th ed). Jakarta: Erlangga Medical Series, 2006; p. 65.

6. Dewoto HR. Pengembangan Obat Tradisional Menjadi Fitofarmaka. Jakarta: Departemen Farmakologi Fakultas Kedokteran Universitas Indonesia, 2007.

7. Rukwana HR. Temu-temuan Apotik Hidup di Pekarangan. Yogyakarta: Penerbit Kinnikus, 2004; p. 10.

8. Valya A. Rahasia Jarak Pagar (Biodiesel). Jakarta: Ganeca Exact, 2007; p. 14.

9. Sarimole E, Martosupono M, Semangun H, Mangimbulude JC. Manfaat Jarak Pagar (Jatropha curcas) sebagai Obat Tradisional. Prosiding Seminar Nasional Raja Ampat. Raja Ampat, Indonesia. 2014. [cited 2015 Oct 15]. Available from: ris.uksw.edu/ 
download/makalah/kode/M01588

10. Prihandana R, Hendroko R. Petunjuk Budi Daya Jarak Pagar. Jakarta: AgroMedia Pustaka, 2006; p. 3.

11. Hambali E, Suryani A, Dadang, Hariyadi, Hanafie H, Reksowardojo IK, et al. Jarak pagar tanaman penghasil biodiesel. Jakarta: Penebar Swadaya,
2006; p. 10.

12. Owoyele BV, Oguntoye SO, Dare K, Ogunbiyi BA, Aruboula EA, Soladoye AO. Analgesic, antiinflamatory and antipyretic activities from flavanoid fractions of Cromolaena odorata. J Med Plants Res. 2008;2(9); 219-25. 